\title{
NOTES FOR AUTHORS
}

The Bulletin of Entomological Research publishes original research papers concerning insects, mites, ticks or other arthropods of economic importance in agriculture, forestry, stored products, biological control, medicine, animal health and natural resource management. The geographical scope of the Bulletin is worldwide but with emphasis on the tropics. Taxonomic papers are accepted if relevant. Short review papers, although normally by invitation, will also be considered for publication.

Page Format. The Bulletin is printed in a two-column format (column width of $80 \mathrm{~mm}$ ) with a text area of $170 \times 225 \mathrm{~mm}$.

Text. Papers should be typed, on one side of the paper only, with double line spacing and ample margins (at least $1.5 \mathrm{~cm}$ ) on each side and with no underlining or bold in text except for scientific names. Draft quality print from a word-processor is not acceptable. Standard abbreviations (e.g. fig. and figs) and metric units must be used. Guidelines for taxonomic papers are available.

When the paper has been accepted word-processed text stored on floppy disk is encouraged, providing the software is IBM/DOS compatible, but floppy discs must be accompanied by a hard copy. This will enable papers to be handled rapidly, and with fewer type-setting errors.

Abstract. Each paper must commence with a carefully prepared, accurate, informative abstract, in one paragraph, that is complete in itself and intelligible without reference to text or figures. It should not exceed 250 words. A short title should be provided as a running head.

Tables. Tables should be reduced to the simplest form, and should not be used where text or illustrations give the same information. They should be submitted on separate sheets at the end of the article and must fit conveniently into single column, full width or landscape (if absolutely necessary) format. Table captions should be typed on a separate sheet.

Illustrations. Copies only of artwork should be submitted. The original illustrations should accompany the paper after acceptance and revision. Text figures, line drawings, computer-generated figures and graphs should be of sufficient size and quality to allow for reduction by half or two-thirds. Half-tone photographs are acceptable where they are a real contribution to the text. Figure and captions should be typed on a separate sheet in the following format:

Figs 23-26. Figs 23-24, Urophora eggs: 23, U. hispanica; 24 U. stigma. Figs $25-26$, spermathecae: 25 , U. maura; 26 , U. stigma; scale lines $=0.05 \mathrm{~mm}$.

Voucher specimens. The deposition of voucher specimens should be considered where appropriate.

References. References must be based on the name and year system, give full journal titles and conform to the following styles:

Powell, W. (1986) Enhancing parasitoid activity in crops. pp. 319-340 in Waage, J. \& Greathead, D. (Eds) Insect parasitoids. London, Academic Press (Symposium, Royal Entomological Society of London No. 13).

Southwood, T.R.E. (1978) Ecological methods with particular reference to the study of insect populations. 2nd edn. 524 pp. London, Chapman \& Hall.

Zhou, X., Carter, N. \& Mumford, J. (1989) A simulation model describing the population dynamics and damage potential of the rose grain aphid, Metopolophium dirhodum (Walker) (Hemiptera: Aphididae), in the UK. Bulletin of Entomological Research 79, 373-380.

Citation of authors in the text should appear in the form: Polaszek (1990) or (Polaszek, 1990). More than one author should be cited in chronological order as: (Holloway et al., 1987; Walker \& Huddleston, 1988).

Offprints. 50 copies of each paper are provided free to the author (or major author) of each paper. Further copies may be obtained on payment, and the number required should be specified and ordered at proof stage.

Manuscripts. Three copies of the manuscript and artwork should be submitted to:

\section{The Editor}

Bulletin of Entomological Research

International Institute of Entomology

56, Queen's Gate

London

SW7 5JR, UK. 


\section{Bulletin of Entomological Research}

Austin, A.G.M., Tatchell, G.M., Harrington, R. \& Bale, J.S. Adaptive significance of changes in morph production during the transition from parthenogenetic to sexual reproduction in the aphid Rhopalosiphum padi (Homoptera: Aphididae).

Barratt, B.I.P., Evans, A.A. \& Johnstone, P.D. Effect of the ratios of Listronotus bonariensis and Sitona discoideus (Coleoptera: Curculionidae) to their respective parasitoids Microctonus hyperodae and M. aethiopoides (Hymenoptera: Braconidae), on parasitism, host oviposition and feeding in the laboratory

Cahill, M., Denholm, I., Ross, G., Gorman, K. \& Johnston, D. Relationship between bioassay data and the simulated field performance of insecticides against susceptible and resistant adult Bemisia tabaci (Homoptera: Aleyrodidae)

Cahill, M., Jarvis, W., Gorman, K. \& Denholm, I. Resolution of baseline responses and documentation of resistance to buprofezin in Bemisia tabaci (Homoptera: Aleyrodidae)

Ferran, A., Rortais, A., Malausa, J.C., Gambier, J. \& Lambin, M. Ovipositional behaviour of Macrolophus caliginosus (Heteroptera: Miridae) on tobacco leaves.

Haggis, M.J. Forecasting the severity of seasonal outbreaks of African armyworm, Spodoptera exempta (Lepidoptera: Noctuidae) in Kenya from the previous year's rainfall.

Hoc, T.Q. A method for the rapid recognition of nulliparous and parous females of haematophagous Diptera.

Kenis, M., Hulme, M.A. \& Mills, N.J. Comparative developmental biology of populations of three European and one North American Eubazus spp. (Hymenoptera: Braconidae), parasitoids of Pissodes spp. weevils (Coleoptera: Curculionidae)

Kerslake, J.E., Kruuk, L.E.B., Hartley, S.E. \& Woodin, S.J. Winter moth (Operophtera brumata (Lepidoptera: Geometridae)) outbreaks on Scottish heather moorlands: effects of host plant and parasitoids on larval survival and development.

Nauen, R., Strobel, J., Tietjen, K., Otsu, Y., Erdelen, C. \& Elbert, A. Aphicidal activity of imidacloprid against a tobacco feeding strain of Myzus persicae (Homoptera: Aphididae) from Japan closely related to Myzus nicotianae and highly resistant to carbamates and organophosphates.

Pener, H. \& Wilamowski, A. Susceptibility of larvae of the sandfly Phlebotomus papatasi (Diptera: Psychodidae) to Bacillus sphaericus..

Turner, C.E., Piper, G.L. \& Coombs, E.M. Chaetorellia australis (Diptera: Tephritidae) for biological control of yellow starthistle, Centaurea solstitialis (Compositae), in the western USA: establishment and seed destruction

Tyndale-Biscoe, M. \& Vogt, W.G. Population status of the bush fly, Musca vetustissima (Diptera: Muscidae), and native dung beetles (Coleoptera: Scarabaeinae) in south-eastern Australia in relation to establishment of exotic dung beetles.

Umoru, P.A., Powell, W. \& Clark, S.J. Effect of pirimicarb on the foraging behaviour of Diaeretiella rapae (Hymenoptera: Braconidae) on host-free and infested oilseed rape plants.

Book Review

C CAB INTERNATIONAL, 1996

All rights reserved. No part of this publication may be reproduced, in any form or by any means, electronically, mechanically, by photocopying, recording or otherwise, without prior permission of the copyright owner. 